\title{
Chronic skull-anchored percutaneous implants in non-human primates
}

\author{
Bryan E. Pfingst ', Tomas Albrektsson ${ }^{2}$, Anders Tjellström ${ }^{3}$. Josef M. Miller '. John Zappia !. \\ Xiaolin Xue ${ }^{1}$ and Franz Weiser ${ }^{1}$

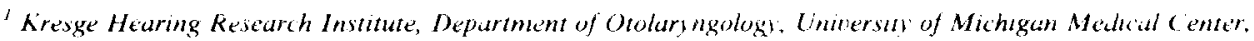 \\ Arn Arbor, MI 48109-0506 (U.S.A.), '2 Biomaterials Group, Department of Handicap Research, University of (sötehorg, Göehorg \\ (Swe'den) and "ENT Department, Sahlgren's Hospital, Iniversity of Göteborg, Göteborg (Sweden) \\ (Received 5 December 1988) \\ (Revised 9 March 1989) \\ (Accepted 12 March 1989)
}

Key words: Percutaneous connector; Bone implant; Bone biology; Osseointegration; Non-human primate: Titanium implant; Stainless steel implant

\begin{abstract}
Three groups of chronic, skull-anchored, percutaneous implants differing in inaterials, design and surgical procedures used for implantation, were tested in macaque monkeys in conjunction with studies of an inner ear stimulation device. Implants from the first two groups in which high-speed drilling methods and stainless steel materials were used, showed a high percentage of failures during the first 3 months after implantation of the percutaneous connector. Implants in the third group, in which measures were taken to preserve living bone tissue, all survived for greater than 7 months. Probable factors relating to implant survival are care of the bone during surgery, postsurgical mechanical trauma, materials and other details of the surgical procedure.
\end{abstract}

\section{Introduction}

Chronic skull-anchored percutaneous implants have a wide variety of applications in both humans and research animals including electrophysiological recording, fluid sampling, head restraint, and electrical, chemical, and mechanical stimulation. In humans, the problems experienced with these implants, such as infection and breakage, have not been trivial, but recent improvements have resulted in reliable stable, infection-free long-term implants in the vast majority of cases (Brånemark et al., 1977, 1984; Tjellström, 1985: Holgers et al., 1988). In research animals, the

Correspondence: B.E. Pfingst, Kresge Hearing Research in. stitute, 1301 East Ann Street, Box 0506, University of Michigan Medical Center. Ann Arbor. MI 48109-0506. U.S.A. problems are greater because hygienic treatment of the implant site by the implanted subject cannot be assured. In freely moving subjects the likelihood of mechanical trauma is also greater in animals than in hurnans. Dislodging of implants is frequent and can result in discomfort to the subject and loss of research time.

In this paper we reported on the results of a long-term retrospective study of percutaneous implants in macaque monkeys. The implants used can be classified into 3 major groups as described in Materials and Methods, below. In groups 1 and II we experienced implant failures in a large percentage of cases within the first 3 months of implantation. but in group III we had no failures during the first 7 months, and only one loss over periods ranging up to 3 years postimplantation. Group III may be divided into 3 subgroups 
(labeled $\mathrm{A}-\mathrm{C}$ ) based on materials used and fine details of technique. Histological analysis has revealed differences in the bony architecture at the implant sites in these subgroups which indicate that group IIIC may have the best prospects for long-term survival.

\section{Materials and Methods}

\section{Overview}

We have tested 50 implants over a 10-year period in adolescent and adult macaque monkeys, both males and females. In all cases, the implants consisted of electrical connectors mounted on the skull and protruding through an opening in the skin. Wires from the base of the connector were led under the skin to an electrode array in the inner ear. The implants may be classified into 3 groups based on similarities in materials and procedures, as detailed below.

All of the animals were behaviorally trained and were tested daily in psychophysical experiments to determine the hearing sensations produced by electrical stimulation of the auditory nervous system (Pfingst et al., 1979, 1985). During behavioral testing sessions, which lasted $2-4 \mathrm{~h} /$ day, the monkeys sat in primate chairs, and at other times they were housed in individual cages. All surgeries were performed using standard sterile procedures in subjects anesthetized with halothane gas.

\section{Implants}

Group I implants (Fig. 1) consisted of an electrical connector fixed to screws in the skull with an acrylic cement. We utilized stainless steel (type 303) machine screws or Vitallium alloy (Howmedica, Rutherford, N.J.) self-tapping screws. Four to seven of these screws were mounted to the skull in holes created with a high-speed surgical drill. The screws were arranged approximately in a circle on the skull with an average diameter of approximately $12 \mathrm{~mm}$. The connector was then cemented to the screws using dental acrylic or methyl methacrylate. Height of the implant averaged $22 \mathrm{~mm}$.

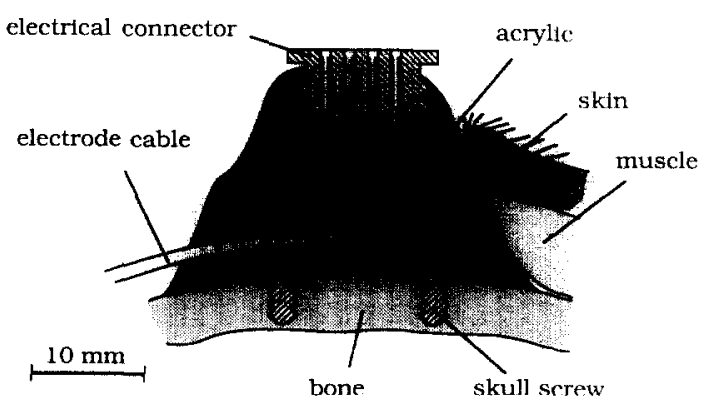

Fig. 1. Diagrammatic representation of a cross-section of an implant from group I mounted on the skull. Typically these implants consisted of a female Amphenol electrical connector mounted on the skull by means of stainless steel or Vitallium alloy screws and acrylic or methyl methacrylate.

Group II implants (Fig. 2) consisted of an electrical connector mounted in a stainless steel (type 316L) cylinder which was attached to the skull using a two-stage procedure. In stage one, 3 stainless steel miniature screws $(2.1 \mathrm{~mm}$ in diameter and $6.4 \mathrm{~mm}$ long) were placed at the implant site. The heads of the screws, which were $3.9 \mathrm{~mm}$ in diameter and $0.8 \mathrm{~mm}$ thick, were inserted under bone, between the inner plate of the calvarium and the dura. Insertion was via a T-shaped defect

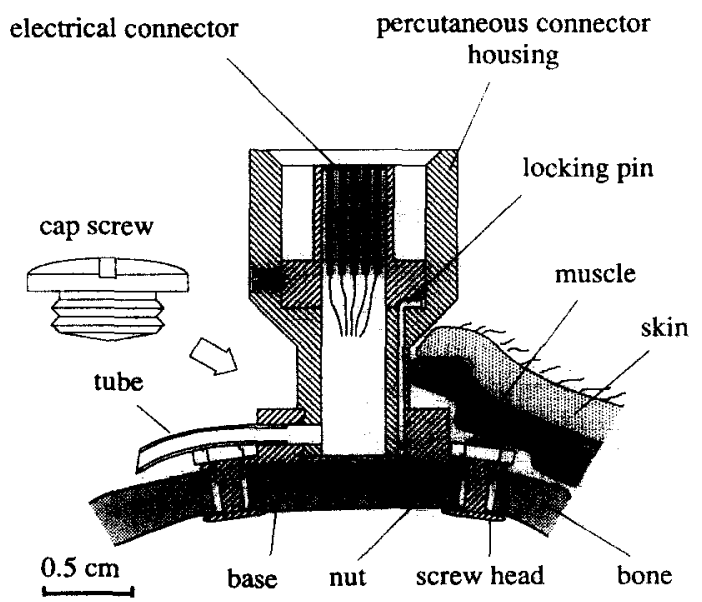

Fig. 2. Diagrammatic representation of a cross-section of an implant from group II mounted on the skull. These implants were mounted in a two-stage procedure in which a base was first mounted on the skull using screws placed with their heads under the bone. After a healing period, the cap screw covering this base was removed and the percutaneous connector-housing was screwed into the base and locked in place with a locking pin. Further details are given in the text. 
in the skull, created with a high-speed drill under profuse irrigation. When in place, the 3 screws formed an equilateral triangle, $12 \mathrm{~mm}$ on a side. A cylindrical stainless steel base with a protective cap screw was secured to the skull using small nuts mounted on these screws. The skin flap was then closed over the base and the implanted area was allowed to heal under the skin for 2-18 months before the percutaneous portion of the implant was placed. To place the percutaneous implant, the scalp was incised to create a circular perforation $7 \mathrm{~mm}$ in diameter. The protective cap screw was removed from the base and the stainless steel percutaneous connector-housing was screwed into the base through this defect and secured with a locking pin. The electrodes and cable were threaded through the housing, through a stainless steel tube under the skin extending from the base of the housing, and then through the mastoid to the middle ear where the electrodes were inserted in the cochlea. Height of this implant above the bone was $25 \mathrm{~mm}$.

Group $I I I$ implants also involved a two-stage procedure, but differed from group II implants in that two special precautions were taken to minimize trauma to bone, both during implantation and after placement of the percutaneous connector. Since it is now known that even moderate heating can kill bone cells (Eriksson and Albrektsson, 1983), all screw holes were created either by drilling at very low speeds by hand, or by a two-stage drilling and cutting process where a small hole was drilled and then enlarged with a cutting bit. Screw holes in the bone were then threaded with a tap, and then the screws were inserted. Profuse irrigation was used during each process to further reduce bone heating. Just before insertion of the screws, a small amount of blood, assumed to contain osteogenic precursor cells, was placed in the hole to facilitate bone growth around the screws after placement.

To minimize mechanical trauma to the bone following placement of the percutaneous connector, the group III implants were designed with a wide base $(24 \mathrm{~mm}$ in diameter) and a low profile on the skull (14 $\mathrm{mm}$ high).

Within group III there were 3 subgroups of implants differing in the materials used and some fine details of procedure. Group IIIA (Fig. 3A) used No. 1 self-tapping type 303 stainless steel screws ( $1.85 \mathrm{~mm}$ diameter by $4.8 \mathrm{~mm}$ length) with the tips ground off, which were mounted in the skull and to which the stainless steel base was anchored with methyl methacrylate. For group IIIB (Fig. 3B), 4 stainless steel tabs on the connector base were attached to the skull with stainless steel screws. We used No. 1 self-tapping screws shortened to various lengths to match the skull thickness. Thus, fixation was achieved without acrylic. Group IIIC implants (Fig. 4) were similar in design to group IIIB, but the implants were made of commercially pure $(99.6 \%)$ titanium. In addition, with group IIIC implants, only the skull screws were placed during stage one in order to

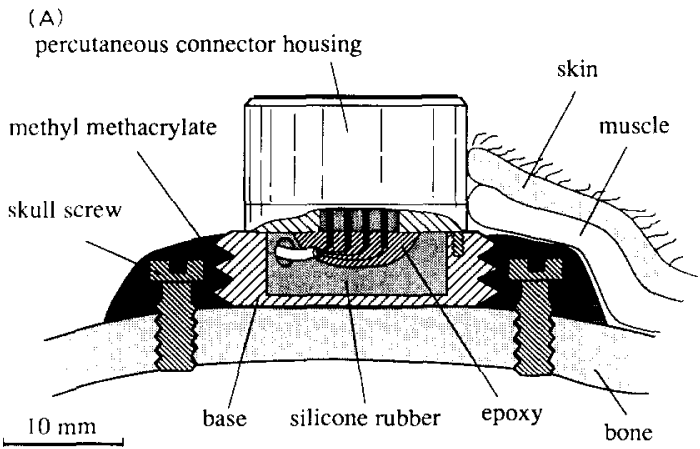

(B)

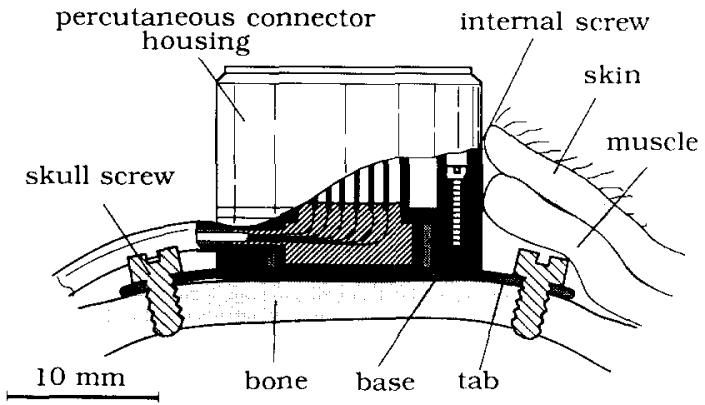

Fig. 3. Diagrammatic representation of group IIIA and IIIB implants. A: in type IIIA, methyl methacrylate was used to secure the stainless steel base to stainless steel screws embedded in the skull. B: in group IIIB, the base was attached directly to the skull by stainless steel screws. In both cases a 12 pin female Microtech connector (type FR-12S-1) was mounted in a stainless steel housing which was attached to the base during a second surgery by means of internal screws. 


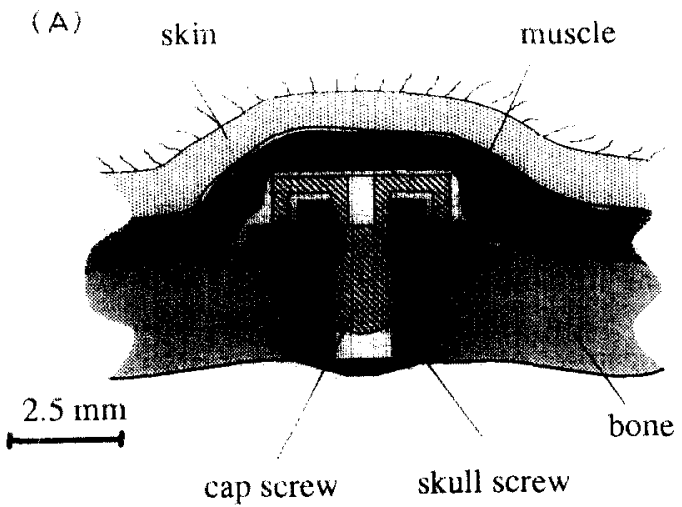

(B)

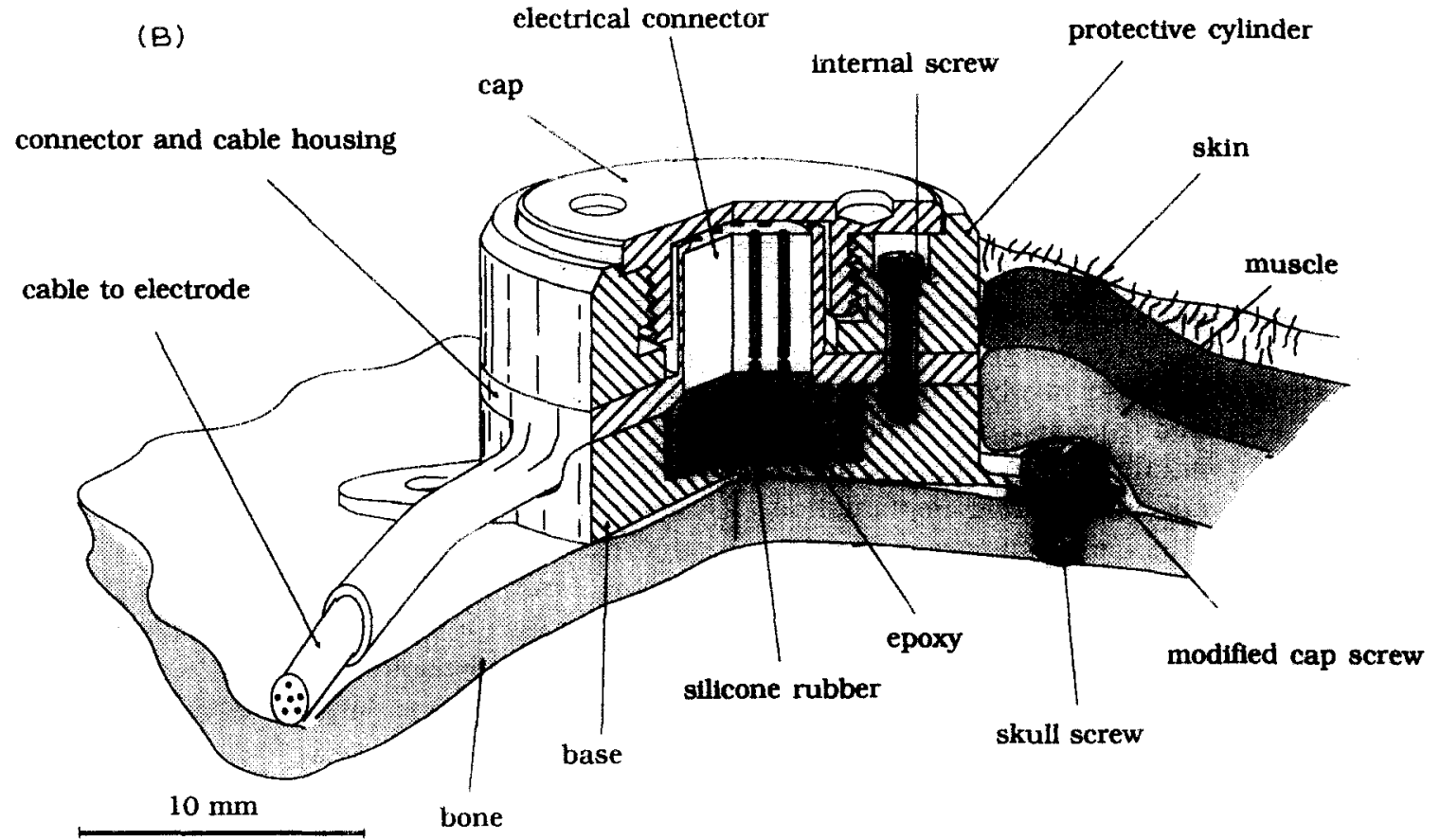

Fig. 4. Diagrammatic representation in a cut-away view of a titanium implant from group IIIC. Only the titanium skull screws (depicted in cross-section in A and on the right side of the diagram in B) are placed during the first surgery. These are covered with a cap screw. The base and percutaneous portion of the implant are then secured to the skull screws during a second surgery using modified cap screws (B). Further details are given in the text.

minimize the load on the screws during the healing period. The titanium skull screws (Fig. 4A) contained a threaded center socket which accepted screws that were used to anchor the base and percutaneous connector during stage two. During stage one, these internal threads were protected by a cap screw. Further details regarding surgical placement of the skull screws is given by Tjellström et al. (1983).
The implant bases, or in the case of group IIIC implants, the skull screws, were left to heal under the skin for periods ranging from 1-5 months. When these screws are used in humans, the minimum recommended healing time before loading is 3 months (Albrektsson et al., 1981). Following this healing period, an incision was made in the skin for placement of the percutaneous portion of the implant. For group IIIA and IIIB 
implants, a circular incision was made over the base, the protective cap screw was removed, the electrodes were threaded through the protective tube connected to the base and under the skin to the middle ear, the well of the base was filled with sterile catalyzed but uncured silicone rubber, and then the percutaneous connector-housing was secured to the base with screws mounted inside the housing (see Fig. 3B). For group IIIC implants, a skin flap was raised, exposing the skull screws. Their protective cap screws were removed and the assembled percutaneous connector (Fig. 4B) was secured to the skull screws using modified cap screws passed through holes in the tabs attached to the titanium base. The undersides of the heads of these modified cap screws were serrated so that they would lock to the tabs when tightened, making them difficult to loosen. After placement of the percutaneous connector, a circular incision was made in the skin flap and the flap was fitted over the implant allowing the protective cylinder to protrude through the circular incision. Margins of the flap were then sutured closed.

Some additional features of the group IIIC implants are worth mentioning. The implants were composed of 3 sections: a base which could be attached to the skull screws by means of tabs, a middle section which housed the connector and implant cable, and a protective cylinder which housed 3 internal screws and to which a threaded protective cap could be secured. These 3 sections were held together by the 3 internal screws, accessible from the top of the implant when the protective cap was removed. The middle section, holding the plug and wires, could be replaced without moving the base. This interchangeable middle section contained a tube through which the electrode wires were threaded. This served to protect the wires as they exited the plug, which is important because monkeys often manipulate the area around the percutaneous connector. The plug and wires were sealed in the middle section of the implant with epoxy to prevent shorting should fluids leak into the base. This epoxy was in turn covered with a layer of silicone rubber. The protective cap on top of the connector was recessed in the connector side walls when screwed on, which effectively prevented the monkey from unscrewing the cap.

\section{Evaluation of implants}

Effectiveness of each implant procedure was assessed largely on the basis of gross analysis: e.g. did the implant remain firmly implanted or did it come loose? In a few cases this was supplemented by histological analysis.

\section{Histological procedures}

The implant sites were examined histologically. at 7-13 months after placement of the percutaneous connector, in one case from group II. 2 cases from group IIIA, and 2 cases from group IIIC. In these cases, following the specified period of implantation, the animals were deeply anesthetized with Nembutal and perfused systemically with saline followed by half-strength Karnovsky fixative. The tissue samples, including the implant and all immediately surrounding bone, were removed, embedded in acrylic resin under vacuum. cut in an Exact sawing machine to a thickness of $100 \mu \mathrm{m}$ and ground in an Exact grinding machine. This method produced sections of a thickness of about $10 \mu \mathrm{m}$ which contained a section of the bone with the titanium implants in place. The sections were made in vertical planes at approximately the centers of the titanium implants. The tissues were stained according to the procedure described by Donath and Breuner (1982) and examined by light microscopy.

\section{Results}

\section{Implant stability}

Of 33 implants in group I. we experienced failures (the implants eventually became dislodged) in 18 cases. Fig. 5A shows a distribution of the times postimplant at which these implants failed. Half of these 18 implants were lost during the first 3 months and the remainder were lost during the following 30 months.

Thirteen of the group I implants remained firmly in place until the subjects were sacrificed for other reasons. The distribution of these sacrifice times is shown in Fig. 5B. In addition, two implants have remained firm in animals maintained in the behavioral experiments for 3 and 7 years at the time of this writing. 
We tested only 7 implants from group II. All of these implants were firm immediately after the second operation where the skin was incised and the percutaneous portion of the implant was attached to the previously implanted base. However, all became loose within a month after this second surgery. Four of these implants were extracted (pulled or knocked out by the subjects) within 6.5 months after implantation of the percutaneous portion of the implant. The other 3 remained in place until sacrifice (at 6 months to 2.6 years), but were unstable at that time and were being supported by braces installed after the implants became loose. X-ray and histological analysis of one of the implant sites after sacrifice revealed that the screws were in fact migrating up through the bone and/or soft tissue so that the base was no longer firmly attached to the skull (Fig. 6). At the time of sacrifice, most of the border zone around this implant consisted of soft tissue, much of which was necrotic. Underneath the implant there was some fibrocartilage formation. The closest dis- tance between bone tissue and metal implant was on the order of $300-400 \mu \mathrm{m}$. In several places there was evidence of soft-tissue inflammation.

All 10 of the implants in group III remained firmly in place for at least 7 months after the percutaneous portion of the implant was attached to the base. In 4 cases, the subjects were sacrificed. with the implants in place, 7-12 months after attachment of the percutaneous portion of the implant, and the skulls were examined histologically (see below). The remaining 6 cases are in animals still being tested as of the time of this writing. In these cases all of the implants are still firm 2-3 years after the second surgery except for one implant from group IIIA that was dislodged 1 year after the second surgery.

\section{Histological analysis of group $I I I$}

Histological examination revealed consistent and significant differences between the implants of group IIIA and group IIIC. Two implants from group IIIA were examined in cases sacrificed 7
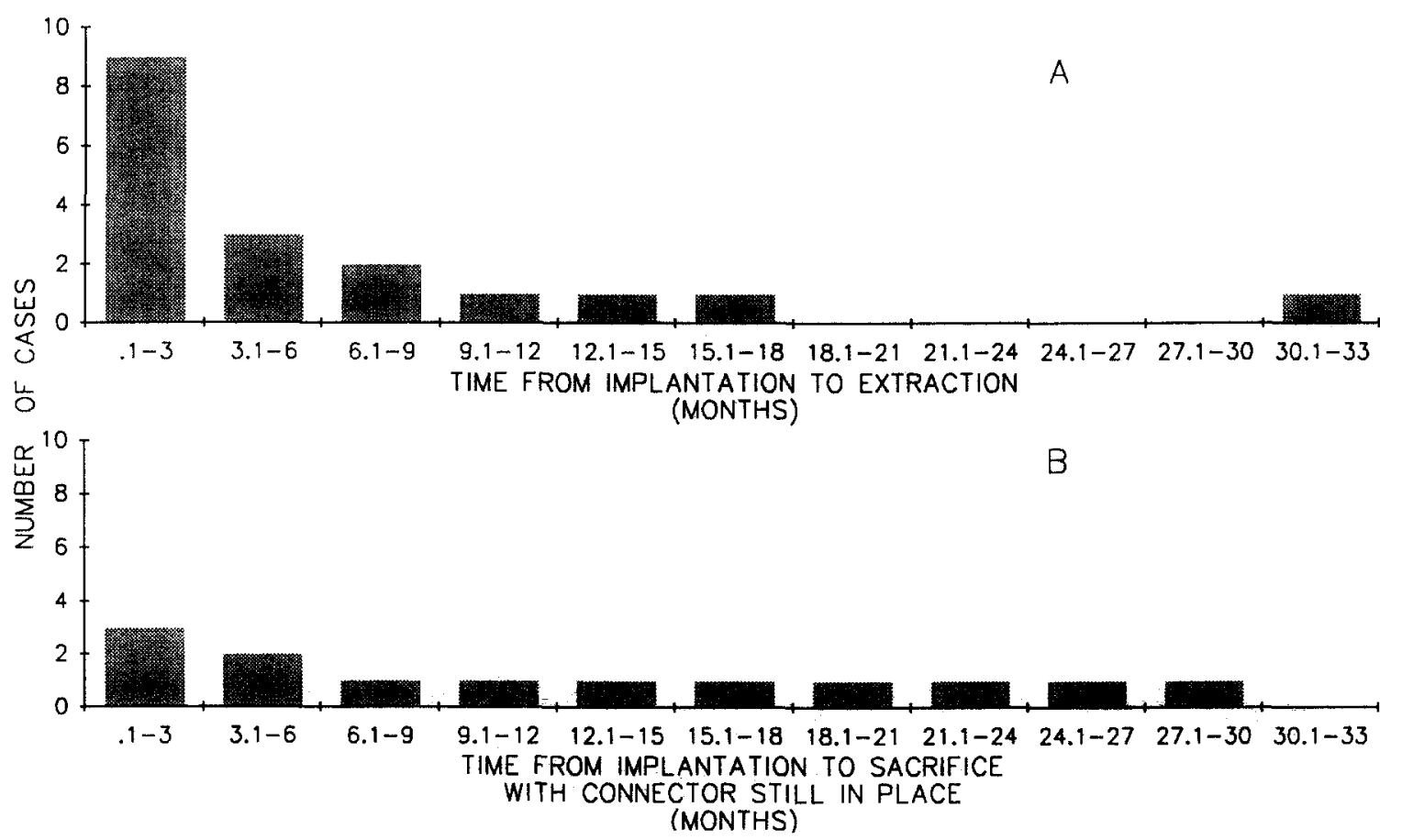

Fig. 5. A: distribution of survival times in months (from connector placement to extraction) for implants from group I. B: distribution of times from connector placement to sacrifice for group I implants which remained in place until the animal was sacrificed. 
and 12 months after placement of the percutaneous connector. In these cases we saw some instances of good contact between the bone and the stainless steel screws, but there were also many instances of gaps at the bone-metal interface (Fig. 7). In 8 samples, the estimated percentage of metal screw surface in contact with the bone averaged $48 \%(s=22$; range $=20-70 \%)$.
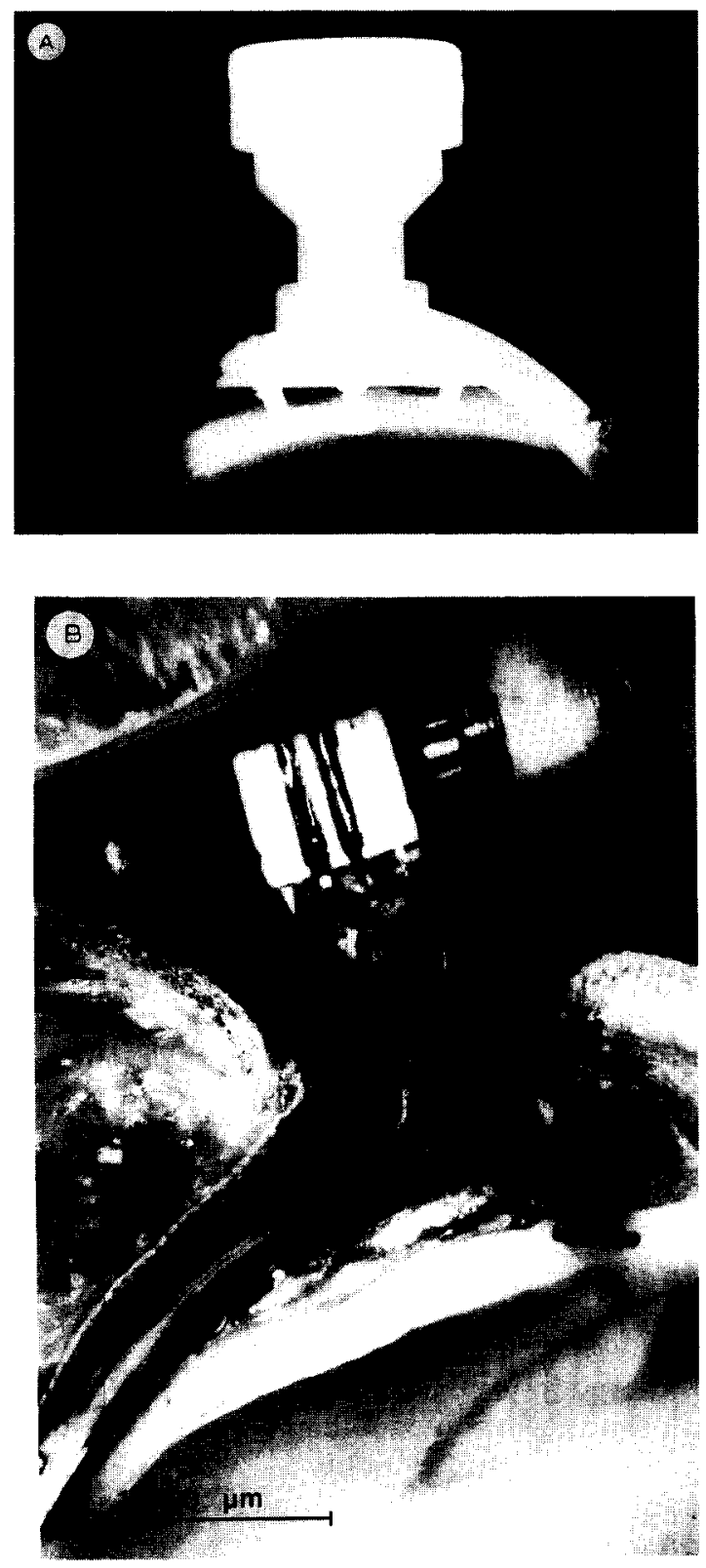

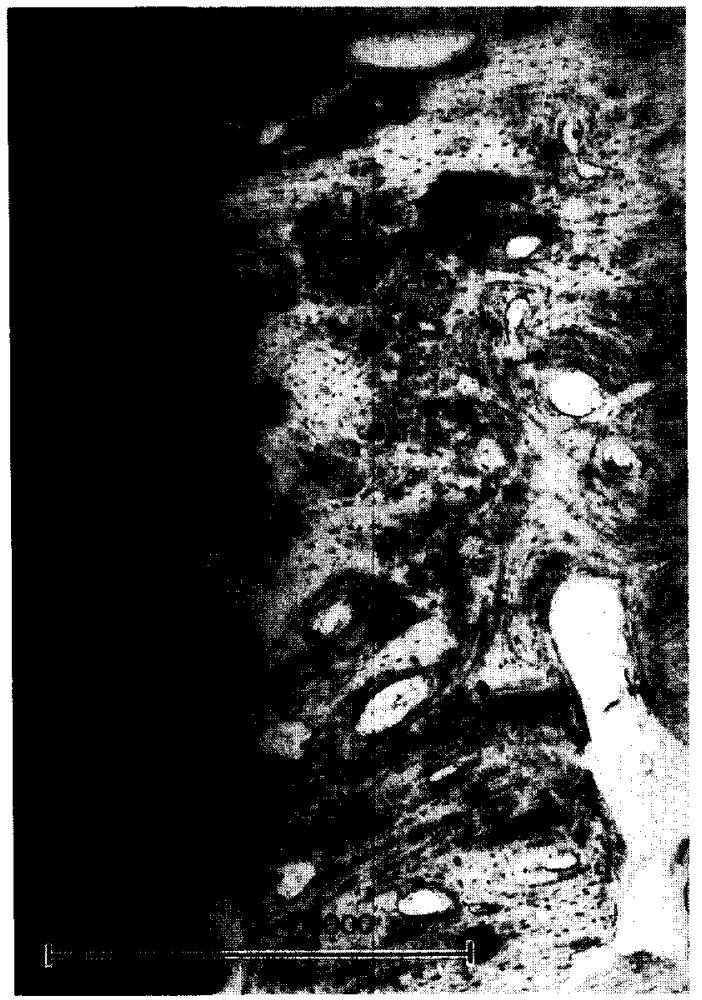

Fig. 7. Section of a stainless steel screw, from a group IIIA implant, mounted in bone. The animal was sacrificed 14 months after the screws were placed in the bone and connected to the stainless steel base with methyl methacrylate, and 12 months after the percutaneous portion of the implant was attached to the implanted base.

Two implants from group IIIC were examined in animals sacrificed 9 and 11 months after placement of the percutaneous connector. Classic os-

Fig. 6. Side views of an implant from group II, made after the animal was sacrificed. The base of this implant was implanted under the skin 2.6 years prior to sacrifice and the percutaneous connector housing was mounted on the base 18 months later (13 months before sacrifice). A: X-rays of the implant in the skull made after the animal was sacrificed and the skull fragment containing the implant was removed. The flat heads of the three screws, which originally had been placed between the underside of the skull and the dura mater (as depicted in Fig. 2), had begun to migrate through the bone toward the surface of the skull. The implant base, which once rested on the bone had subsequently become separated from the top of the skull. B: a cross-section made through the approximate center of the implant and bone after the specimen had been embedded in plastic. 
seointegration (Brånemark et al., 1977; Albrektsson et al., 1981) of the titanium skull screws with the bone of the skull was seen (Fig. 8). This was
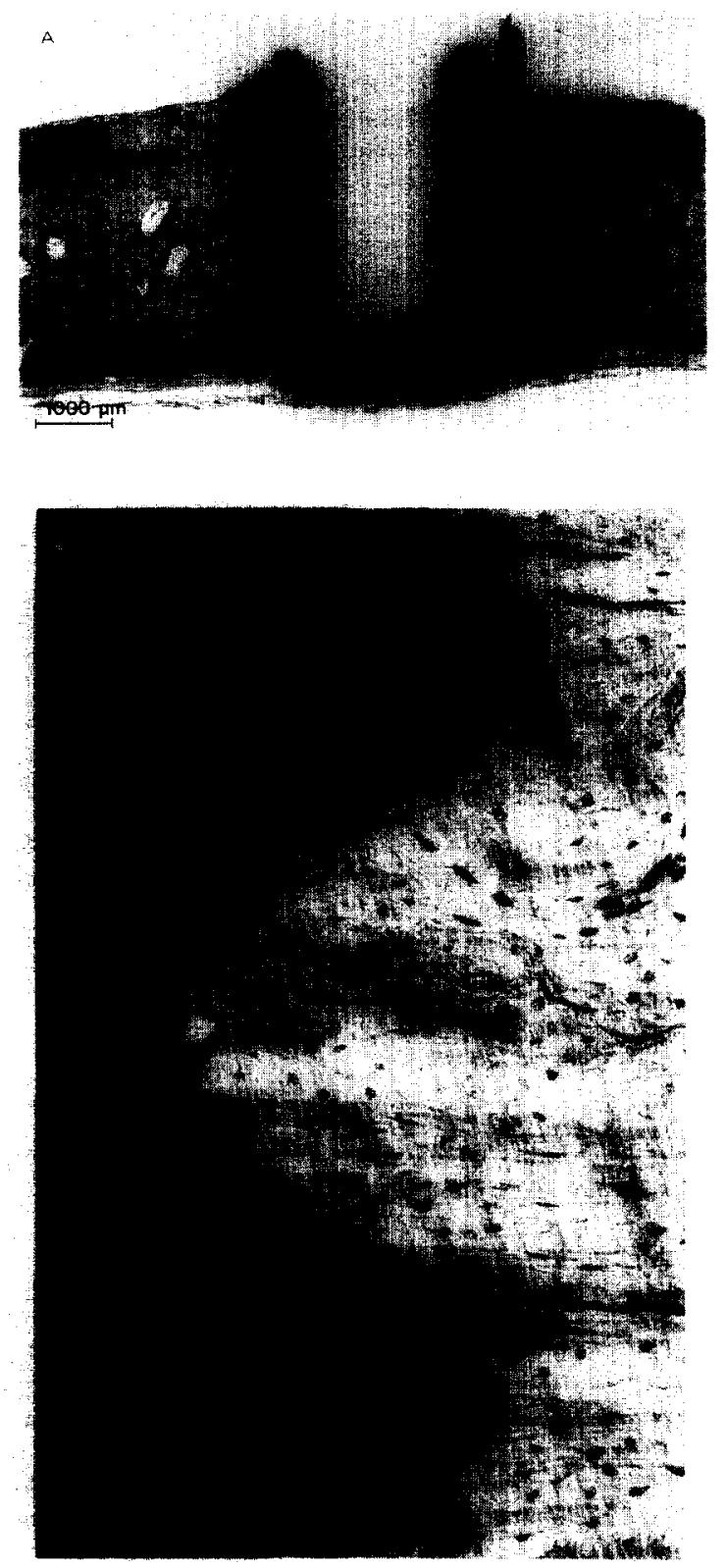

Fig. 8. Cross-sections of a skull screw from a group IIIC implant, mounted in bone. A shows a cross-section of a whole skull screw and B shows an enlarged view of one side of the same screw. Some new bone growth near the screw is evident. The animal was sacrificed 11 months after the screws were placed in the bone and 9 months after the percutaneous portion of the implant was attached to the skull screws. characterized by ordered haversian bone in direct contact with the oxidized surface of the titanium skull screws. Numerous osteocyte lacunae were seen in the bone near each of the screws. Of the 8 skull screws examined in these cases all showed almost $100 \%$ bone contact with the shaft of the screw as it passed through the cortex of the bone. Only at the top and bottom ends of the screws was any soft tissue seen in contact with the screw (Fig. 8A).

\section{Discussion}

Clear improvements in long-term implant stability were seen in group III implants as compared to groups I and II. In groups I and II we experienced a high percentage of failures within the first 3 months after placement of the percutaneous connector. Since 3 of the animals in group I were sacrificed (for other reasons) before 3 months, we cannot specify the percentage of loss exactly. However, if we make the extreme assumptions that in either all or none of these 3 cases the implants would have survived for 3 months, the total percent of failures within the first 3 months would range from 27 to $36 \%$. Applying these same assumptions over a 7 month period for group I implants, the range of loss would be $36-55 \%$. Under either assumption, the percentage lost is unacceptable. The fact that $10(30 \%)$ of these group I implants survived for at least a year and one survived for more than 7 years, suggests that early failure of these devices is not inevitable, but the failure rate is much too high for most long-term research projects. In contrast, all of the $10 \mathrm{im}$ plants in group III survived for periods exceeding 7 months. The longer term prospects for these implants varies depending on other details of technique, and is excellent for type IIIC.

Since the implant designs and procedures differed in several respects among groups I, II and III, it is not possible to specify the degree to which each factor contributed to implant stability or lack there of. However, from our own experience and that of others, we strongly suspect two variables as playing major roles: heating of the bone during 
the drilling prior to screw insertion and trauma caused by subjects bumping the implants against hard objects.

Heating of bone by as little as $7-8^{\circ} \mathrm{C}$ above normal body temperature for one minute has been demonstrated in rabbit tibia to kill osteocytes (Eriksson and Albrektsson, 1983). From less rigorous observations we have observed that when implants in group I were placed in bone which was heated severely by high-speed drilling with inadequate irrigation, they became dislodged after a month or two whereas, when more care was taken to reduce heating, implants lasted much longer. The most ideal procedures of the experiments reported here were those practiced in group III in which drilling was done at low speeds and/or in multiple stages with the final stage being a low speed tapping of the hole and with profuse irrigation used at all stages.

Mechanical trauma to the implants was quite common in freely moving animals. This was evident from observing the implants from group I which consisted of a hard plastic connector mounted on the skull. Over a period of months these connectors became scratched and worn around their entire circumference, apparently from repeated striking against the metal cages in which the animals were housed. Mechanical trauma was reduced in the implants in group III by lowering the height of the implant to reduce the possibility of lateral blows and widening the base to reduce the lever ratio should the implant be hit laterally. The height of the group III implants (about 14 $\mathrm{mm}$ ) was as short as was practical for adolescent or adult macaques, as it typically protruded only 1-2 $\mathrm{mm}$ above the skin. In fact, in some larger animals, it was necessary to undercut the muscle layer around the implant to keep the soft tissue below the top of the plug. Because of this close proximity to the skin surface, we designed the connector-housing so that all operations could be performed from the top without touching the sides of the housing or the surrounding skin.

The observed differences in histology between subgroups IIIA and IIIC may be expected to relate to the long-term stability of the implants. The bone in group IIIC, in addition to being more tightly bound to the metal screws, also appeared healthier. The differences between groups IIIA and IIIC might be attributable to any or all of several factors. First, the methyl methacrylate used in group IIIA may have damaged the bone either through a slight heating during curing or by leaching toxic substances into the bone (Linder. 1976: Albrektsson and Linder, 1984). The presence of gaps between the bone and the screw threads in some cases in group IIIA may have been due to less precise tapping of the holes with the hand-held tap (as compared with the machine driven tap in group IIIC), or it may be related to the differences in materials (stainless steel vs titanium, Albrektsson and Hansson, 1986) or may simply reflect the poor condition of the bone as described above. Since new bone growth was commonly seen next to the screw threads in several type IIIC implants. we suspect that a precise initial fit was not critical. Other variables which may have contributed to the differences between groups IIIA and IIIC include differences in the initial loading of the screws (presence or absence of the implant base during the initial healing period) and duration of the healing period before the percutaneous connector was placed.

Further research is needed to determine the relative importance of many of the differences among the group III implants. At this time we have insufficient data on group IIIB to adequately compare it with groups IIIA and IIIC.

Another consideration which deserves further study is the condition of the skin around the percutaneous connector. In some cases we have seen good healing of the skin in close proximity to the percutaneous connector while in other cases we have observed some skin recession and/or occasional infection. At this time it is not clear what variables contribute to these differences.

In humans, titanium implants of the type used in these experiments have been used to successfully anchor percutaneous implants for periods exceeding 10 years with virtually no failures (Tjellström, 1989). After $1-3$ years in monkeys these implants seem to be extremely healthy. offering promise for similar success rates in this more difficult case. 


\section{Acknowledgements}

This work was supported by NIH Grant NS21440 and by grants from the Swedish Medical Research Council and the King Gustaf Jubilee Foundation. We express thanks to Clifford Astley, Carina Johansson, José Nuncio-Cantera, Daniel Rai, Nancy Rush, and Thomas Susor for technical assistance in this research, and to John Niparko and Brad May for their helpful comments on earlier versions of the manuscript.

\section{References}

Albrektsson, T., Bränemark, P-I., Hansson, H-A. and Lindström, J. (1981) Osseointegrated titanium implants. Requirements for ensuring a long-lasting, direct bone-toimplant anchorage in man, Acta Orthop. Scand., 52: 155-170.

Albrektsson, T. and Linder, L. (1984) Bone injury caused by curing bone cement. A vital microscopic study in the rabbit tibia, Clin. Orthop. Relat. Res., 183: 280-287.

Albrektsson, T. and Hansson, H-A. (1986) An ultrastructural characterization of the interface between bone and sputtered titanium or stainless steel surfaces, Biomaterials, 7: 201-205.

Brănemark, P-I., Adell, R., Albrektsson, T., Lekholm, U., Lindström, J. and Rockler, B. (1984) An experimental and clinical study of osseointegrated implants penetrating the nasal cavity and maxillary sinus, J. Oral Maxillofac. Surg., 42: 497-505.

Brånemark, P-I., Hansson, B.O., Adell, R., Breine, U., Lindström, J., Hallén, O. and Öhman, A. (1977) Osseoin- tegrated implants in the treatment of the edentulous jaw. Experience from a 10-year period, Scand. J. Plast. Reconstr. Surg., 11: 1-132.

Donath, K. and Breuner, G. (1982) A method for the study of undecalcified bones and teeth with attached soft tissues, $J$. Oral Pathol., 11: 318-326.

Eriksson, A.R. and Albrektsson, T. (1983) Temperature threshold levels for heat-induced bone tissue injury: a vital-microscopic study in the rabbit, J. Prosthet. Dent., 50: $101-107$.

Holgers, K-M., Tjellström, A., Bjursten, L.M. and Erlandsson. B-E. (1988) Soft tissue reactions around percutaneous implants: a clinical study of soft tissue conditions around skin-penetrating titanium implants for bone-anchored hearing aids, Am. J. Otol., 9: 56--59.

Linder, L. (1976) Bone Cement Monomer, Thesis, Göteborgs Universitet, Sweden.

Pfingst, B.E., Donaldson, J.A., Miller, J.M. and Spelman, F.A. (1979) Psychophysical evaluation of cochlear prostheses in a monkey model, Ann. Otol. Rhinol. Laryngol., 88: 613-625.

Pfingst, B.E., Glass, I., Spelman, F.A. and Sutton, D. (1985) Psychophysical studies of cochlear implants in monkeys: clinical implications. In R.A. Schindler and M.M. Merzenich (Eds.), Cochlear Implants, Raven, New York, pp. 305-321.

Tjellström, A. Osseointegrated systems and their applications in the head and neck, Ad. Otolaryngol. Head Neck Surg., 3: $39-69$.

Tjellström, A., Rosenhall, U., Lindström, J., Hallén, O., Albrektsson, T. and Brănemark, P-I. (1983) Five-year experience with skin-penetrating bone-anchored implants in the temporal bone, Acta Otolaryngol., 95: 568-575.

Tjellström, A. (1985) Percutaneous implants in clinical practice, CRC Crit. Rev. Biocompat., 1: 205-228. 